\title{
Historia
}

\section{Anayde Corrêa de Carvalho: legado histórico para a enfermagem brasileira}

\section{Anayde Correa de Carvalho: historical legacy for the Brazilian Nursing \\ Anayde Correa de Carvalho: herencia histórica para la Enfermería brasileña}

Taka Oguisso을 Paulo Fernando de Souza Campos², Emiliane da Silva Santiago ${ }^{3}$, Luciana Barizon Luchesi ${ }^{4}$. ${ }^{1}$ Enfermeira. Professora Titular da Escola de Enfermagem da Universidade de São Paulo (EEUSP). Presidente da Academia Brasileira de História da Enfermagem (ABRADHENF), 2010-12 e 2012-2014. Correspondencia: Departamento ENO, Escola de Enfermagem da Universidade de São Paulo, Av. Dr. Enéas de Carvalho Aguiar, 419 - 05403-000 - São Paulo - SP. Correo electrónico: takaoguisso@uol.com.br.

${ }^{2}$ Historiador. Doutor em História. Pós-doutorado no Departamento de Orientação Profissional, da Escola de Enfermagem da USP. $1^{\circ}$ Secretario da Academia Brasileira de História da Enfermagem (ABRADHENF) - 2010-2012. Correo electrónico: pfsouzacampos@usp.br

${ }^{3}$ Enfermeira, Profa. Ms. do Departamento de Enfermagem em Educação e Saúde Comunitária do Curso de Graduação em Enfermagem da Universidade Federal do Triângulo Mineiro-UFTM. Doutoranda do Programa de Enfermagem Psiquiátrica, EERP-USP. Ribeirão Preto-SP, Brasil. Correo electrónico:emilianesant@usp.br

${ }^{4}$ Enfermeira. Professora Doutora do Departamento de Enfermagem Psiquiátrica e Ciências Humanas, da Escola de Enfermagem de Ribeirão Preto, da Universidade de São Paulo. Diretora de Assuntos Científicos e Culturais da Academia Brasileira de História da Enfermagem (ABRADHENF), 2010-12 e 2012-14. Correo electrónico: luchesi@eerp.usp.br

Cómo citar este artículo en edición digital: Oguisso, T; de Souza Campos, P.F; da Silva Santiago, E; Barizon Luchesi.E. (2013) Cultura de los Cuidados (Edición digital)17, 37. Disponible en: <http://dx.doi.org/10.7184/cuid.2013.37.04>

Correspondencia: Taka Oguisso. Departamento ENO, Escola de Enfermagem da Universidade de São Paulo, Av. Dr. Enéas de Carvalho Aguiar, 419 - 05403-000 - São Paulo - SP.

Correo electrónico: takaoguisso@uol.com.br.

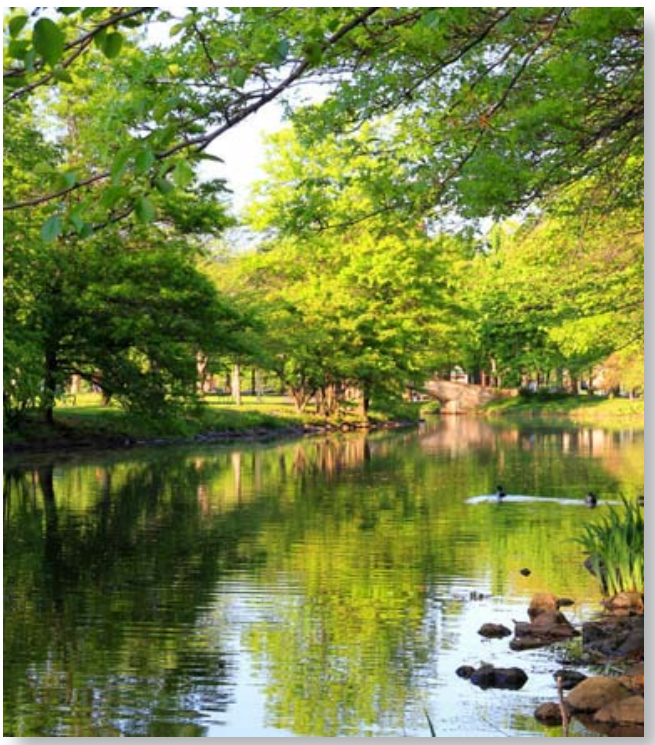

\section{ABSTRACT}

The biographical narrative is one of the most traditional perspectives of the historical writings. Its methodological renovation means the rescue of the historical trajectories less known, utilizing new documental sets for this activity, such as the oral history. This paper intends to articulate within the scope of the Life Oral History, individual and collective happenings characterized by the personal experience of a nurse who lived the nursing professionalization in Brazil post-1930 - Anayde Correa de Carvalho. The outcomes of this reflection allow considering not only her interpretation about the first associative movements related 
to the Brazilian nursing which she reported through an extensive documentary but also her production and life experience have contributed to conforming the professional identity of the Brazilian Nursing.

Keywords: Biography, Nursing Schools, Nursing History

\section{RESUMEN}

La narrativa histórica es una de las más tradicionales perspectivas de la historia escrita. Su renovación metodológica implica rescatar trayectorias históricas poco conocidas, utilizándose para esa actividad nuevos conjuntos documentales, como es el caso de la oralidad. Este texto intenta articular, en el ámbito de la Historia Oral de Vida, acontecimientos individuales y colectivos caracterizados por la experiencia personal de una enfermera que ha vivido la profesionalización de la enfermería en Brasil, post-1930 - Anayde Correa de Carvalho. Los resultados de la reflexión permiten considerar no solamente sus interpretaciones registradas en un extenso documentario sobre los primeros movimientos asociativos de la enfermería brasileña, como su producción y experiencia de vida contribuyeron para la formación de la identidad profesional de la enfermería brasileña.

Palabras clave: Biografía. Escuelas de Enfermería. Historia de la Enfermería.

\section{RESUMO}

A narrativa biográfica é uma das mais tradicionais perspectivas da escrita da história. Sua renovação metodológica implica recuperar trajetórias históricas pouco conhecidas, utilizando, para essa atividade, novos conjuntos documentais como, no caso, provenientes da oralidade. Este texto pretendeu articular, no âmbito da História Oral de Vida, aconteci- mentos individuais e coletivos, caracterizados pela experiência pessoal de uma enfermeira que vivenciou a profissionalização da enfermagem no Brasil pós-1930 - Anayde Correa de Carvalho. Os resultados da reflexão permitem considerar não só suas interpretações registradas, em um extenso documentário, sobre os primeiros movimentos associativos da enfermagem brasileira como também sua produção e experiência de vida contribuíram para a formação da identidade profissional da enfermagem brasileira.

Palavras chave: Biografia; Escolas de Enfermagem; História da Enfermagem.

\section{INTRODUÇÃO}

Este trabalho teve por objetivo ensaiar um novo olhar sobre a memória da construção da identidade profissional da enfermagem no Brasil, pós-1930, contextualizar o momento histórico em que os fatos se passaram e colaborar para a preservação da memória de pioneiras da enfermagem, em especial daquelas que desenvolveram grande parte dos trabalhos nos bastidores. Ou seja, vislumbrar a história a partir da perspectiva do movimento da História Nova, dando voz aos que ficaram à margem da história, dita oficial.

Trata-se de estudo de natureza histórica e biográfica, para melhor conhecer a figura de Anayde Corrêa de Carvalho, que deixou como legado um livro chamado "Associação Brasileira de Enfermagem - Documentário - 1926-1976”, publicado em 1976, com 514 páginas (Carvalho, 1976). Ao descrever os primeiros cinquenta anos de história dessa organização, trabalho esse de cinco anos de pesquisas, reproduziu minuciosamente a própria História da Enfermagem Brasileira e das líderes que forjaram os destinos da profissão no período estudado. 
A autora soube retratar e documentar com fidelidade e clareza a saga e as lutas das pioneiras da Enfermagem. Realizou o estudo com objetividade e rigoroso critério em todas as etapas da busca de documentos. Na ausência de documentos, obteve dados através de entrevistas com enfermeiras que haviam vivenciado os fatos e que ainda tinham capacidade para informar, na ocasião. Reconstruiu a história da Associação Brasileira de Enfermagem (ABEn), tarefa que hoje seria muito difícil de refazer, ou mesmo complementar a história das décadas subsequentes, pela complexidade atual, simultaneidade e multiplicidade na ocorrência de fatos.

Apesar da importância da obra, a autora é praticamente desconhecida pelas gerações atuais da Enfermagem. Não recebeu a devida atenção por parte da maioria dos líderes da profissão, apesar de ter contribuído com seu rigoroso espírito científico e metodológico, disciplina, talento e capacidade de trabalho. Contudo, para Anayde Corrêa de Carvalho, o trabalho de cinco anos de pesquisa para escrever o livro foi considerado apenas o cumprimento de um dever e que isso não a tornava merecedora de homenagens.

Deve-se destacar que o relato da história da ABEn, da profissão e das profissionais que a conformavam à época, contidos em sua obra, ajudou a delinear a construção da identidade da Enfermagem profissional brasileira de hoje. A segunda edição dessa obra foi publicada pela ABEn, em 2006. No entanto, o conteúdo pelo qual a autora é responsável não foi alterado, houve o acréscimo de um depoimento de Prof ${ }^{a}$ Dr ${ }^{a}$ Ieda de Alencar Barreira, na contracapa (Barreira, 2006) e uma Nota sobre a Autora, no final do livro, de autoria da Prof ${ }^{a}$ Dr $^{\text {a }}$ Taka Oguisso (Oguisso, 2006).

Por pertencer à mesma família de uma grande líder da enfermagem brasileira, na qualidade de irmã de Amália Correa de Carvalho, colocou-se sempre na retaguarda, dando apoio e sustentação à irmã mais nova. Enquanto Amália estava no palco diante dos holofotes, na qualidade de presidente, seja da Associação Brasileira de Enfermagem, seja do Conselho Federal de Enfermagem, ou por seu trabalho como consultora de organizações internacionais de saúde ou na coordenação de programas de pós-graduação na Escola de Enfermagem da Universidade de São Paulo (EEUSP), Anayde Corrêa de Carvalho continuava nos bastidores, oferecendo apoio em silêncio. Mesmo sem tal intenção consciente, ajudou a construir a Enfermagem brasileira e exerceu grande influência na formação de várias gerações de enfermeiros, especialmente na área de administração/gerenciamento de enfermagem.

O interesse por conhecer, desvelar e relatar a participação de Anayde Correa de Carvalho na Enfermagem brasileira teve o propósito de produzir conhecimento sobre a vida profissional de uma das pioneiras mais ativas e atuantes, embora quase sempre de forma invisível. Seu legado mais visível é, sem dúvida, o livro por ela produzido, cuja primeira edição foi inteiramente doada à Associação Brasileira de Enfermagem (ABEn), considerado uma obra clássica pela literatura, especialmente em história da enfermagem. Trata-se da mais fidedigna e monumental obra sobre a ABEn, pelo volume de informações e dados coletados, com registro minucioso de meio século de vida, de lutas e conquistas da ABEn, reconhecida por Barreira (2006) como "patrimônio" que deveria ser passado às novas gerações de enfermeiros e que, em mais de trinta anos de consultas frequentes não localizou informações contraditórias". Mesmo considerada uma "obra preciosa" e "um tesouro que pertence a todos 
nós” (Barreira, 2006), sua autora continua na surdina. Portanto, este estudo busca minorar a falta de publicações sobre enfermeiras que contribuíram significativamente para o avanço da profissão e que servem de inspiração para os futuros enfermeiros, contribuindo, dessa forma, para a construção da identidade profissional da enfermagem.

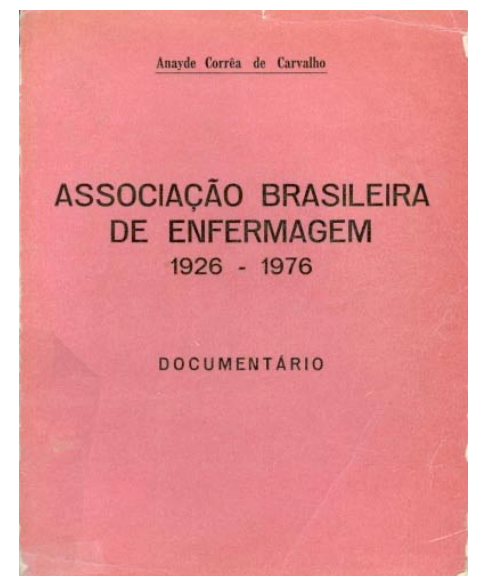

Figura 1 - O livro "Associação Brasileira de Enfermagem, 1926-1976 - Documentário"

\section{METODOLOGIA}

Trata-se de estudo de natureza histórica e biográfica, utilizando-se da metodologia da História Oral de Vida, originária dentro do Movimento da História Nova, onde o foco remete à história de vida do sujeito e possui estreita relação com o método biográfico (Meihy, 2002). A História Nova tem como meta dar voz às pessoas, minorias sociais, entre outros, que não foram contemplados pelos holofotes da história dita oficial, mas cuja contribuição ou percepção, em relação a determinados fatos históricos, permite um novo olhar para a história, um olhar de baixo para cima, uma história de bastidores e não de palcos. Nesse sentido, são fontes para o presente estudo, não somente as entrevistas realizadas, mas, ainda, documentos, livros, artigos e outros materiais que possam retratar a vida e obra de Anayde Correa de Carvalho.

Esse método tem estreita relação com os estudos biográficos que são um recurso metodológico para "conhecer, interpretar e representar a história da humanidade... e constitui uma maneira de relatar a história. Portanto, a construção de biografias atende ao interesse de resgatar e compreender a história da enfermagem" (Sanna, 2011).

O estudo foi aprovado pelo Comitê de Ética em Pesquisa da Escola de Enfermagem da Universidade de São Paulo, dentro de um projeto que atualmente consta como parte do Protocolo 888/2010/CE-EEUSP, sob o título "Memória da Enfermagem Brasileira e em São Paulo".

A primeira entrevista foi realizada em 19 de abril de 2009, houve utilização de roteiro semiestruturado, e a entrevistada recebeu a transcrição da primeira entrevista para correções, sugestões e cortes como preconizados por Meihy (2002).

Observando-se o não esgotamento dos temas a serem trabalhados na primeira entrevista, outras duas entrevistas foram realizadas, em 2010 e 2011, pela primeira autora para coleta de dados da biografada. Nas duas entrevistas houve a presença de Maria José Schmidt e de Irmã Maria Tereza Notarnicola, ambas enfermeiras, amigas de longa data que gozam da confiança da entrevistada e facilitaram o processo da entrevista. Apenas as versões revisadas e autorizadas pela entrevistada foram analisadas.

Nesse sentido, o presente estudo teve como desafio analisar a vida de uma líder quase invisível da Enfermagem Brasileira e deixar registrada a vida dessa profissional para as futuras gerações. Entretanto, concluído o trabalho, 
Anayde Corrêa de Carvalho não concordou com a publicação, por achar que estava se expondo demais. Naquele momento, seguindo os pressupostos éticos, foi decidido hibernar o artigo. Em julho de 2013, às vésperas de completar 97 anos de idade, mantendo sua lucidez, e após pequenos ajustes e atualizações no texto, ela concordou com a publicação.

Após a coleta dos dados, foi utilizada a análise de conteúdo do discurso, a fim de organizar e discutir os achados, utilizando-se, como referencial para essa análise, a técnica preconizada por Bardin (2008). Entre as categorias escolhidas para este estudo, com base nas entrevistas, encontram-se: analítica, operacional e empírica. A categoria analítica está descrita como trajetória acadêmica, trajetória profissional e visão futurista. Seria a categoria por excelência para a análise pretendida.

\section{RESULTADOS E DISCUSSÃO}

\section{Categoria trajetória acadêmica}

Anayde Corrêa de Carvalho nasceu em Ribeirão Preto, no dia 20 de julho de 1916, filha de Pedro Correa de Carvalho e Elza Morandini de Carvalho, de ascendência alemã, portanto, muito rígida na educação dos sete filhos: Augusta, Mariana, Anayde, Amália, Manoel Francisco, Maria e Pedro. A mais velha, Augusta, faleceu com apenas 31 anos, em 1944, deixando três filhos pequenos. Passou sua infância na fazenda do pai e estudou no Colégio Santa Úrsula. O pai faleceu em 1956, de embolia pulmonar e a mãe em 1989, com 89 anos de idade. Após os estudos de nível fundamental nesse Colégio, completou o antigo curso normal, para formação de professores de nível primário, chegando a lecionar por algum tempo em escola primária.

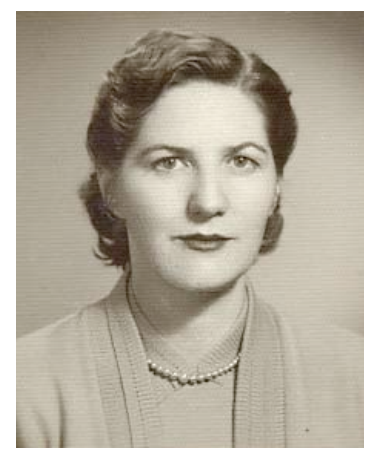

Figura 2 - Anayde Correa de Carvalho, ao tempo em que iniciou sua carreira como enfermeira. Fonte: Arquivo pessoal de Anayde Correa de Carvalho. Fotógrafo desconhecido.

Sobre sua escolha pela enfermagem, a colaboradora explica: "Bom, na realidade eu não escolhi a enfermagem. Eu fui mais ou menos induzida por minha irmã, Amália, que já estava na Escola e dizia gostar demais do curso. Cada vez que ela vinha para casa, eram só elogios ao curso de enfermagem que estava fazendo. Achava as matérias muito interessantes e que o trabalho também era muito edificante, quer dizer, satisfazia. Então meu pai sugeriu que eu também fosse estudar enfermagem na mesma Escola (...). Fui e gostei muito do curso. Gostei também da profissão. Depois de formada, trabalhei um pouco no HC (Hospital das Clínicas, da Faculdade de Medicina da Universidade de São Paulo) e depois fui chamada por D. Edith (de Magalhães Fraenkel) a ir para a Bahia, na Escola de Enfermagem que havia sido recentemente criada (atual Escola de Enfermagem da Universidade Federal da Bahia). Trabalhei dois anos lá (...). depois voltei para EE (USP) e fiquei lecionando Enfermagem Médica, mas a maior parte de minha atuação na Escola foi lá, no que chamávamos, (na época) de escritório técnico. Penso que ainda deve existir (algo parecido) lá na escola, eu acho. Era uma área que se relacionava mais com o professor, providenciar paga- 
mentos pelas aulas (de professores externos ou de não enfermeiros contratados), manter comunicação, fazer escalas e rodízio de aulas, enfim a parte burocrática (das atividades técnicas e docentes)".

Parece que a vida acadêmica apresentou-se atraente para a jovem interiorana que viera de Ribeirão Preto para São Paulo com o intuito de estudar. Foi estudante da EEUSP, residindo no internato, então existente, e na entrevista recordou sobre as boas lembranças desse período, inclusive sobre a rigidez a que todas as internas estavam submetidas. Considerou ter sido uma experiência tão gratificante que, quando se tornou enfermeira docente da Escola, continuou morando nela. Sobre a rígida disciplina comenta: "Era bom. Eu gostava. Tinha horário para tudo. Quando eu era aluna, às $10 h$ (da noite) tinha que estar dentro da escola. E tinha uma pessoa responsável para verificar se a gente estava ou não na escola às 10h da noite. Porque às 10 horas eram apagadas todas as luzes. Dormir às 10 horas para todo mundo acordar de manhã às 6h. A obrigação era dormir 8 horas por noite. Eram 8 horas de trabalho, 8 horas de estudo e 8 horas de sono. Era uma vida muito saudável! Tanto que depois como professora eu continuei a morar na escola por mais algum tempo".

Sobre as diferenças entre estudantes de enfermagem de sua época e o momento atual, e o perfil das alunas de hoje, a colaboradora considerou: "Nossa! Mas mudou demais. No nosso tempo, eu era muito disciplinadora porque assim havia aprendido. E as nossas alunas eram bem disciplinadas também. Elas ficavam direitinho nas salas de aulas, assistindo às aulas. Hoje não! Há muita bagunça nas salas de aula, e nas próprias aulas. Agora cada um vai (vestido) do jeito que quiser e senta do jeito que quiser. Eu sei lá, mudou muito. Mudou demais”.
Em relação aos profissionais de enfermagem, a colaboradora comentou: "Talvez tenha mudado até para melhor, porque ficou mais cientifico, mais relacionado com o estudo, (levando ao) maior desenvolvimento da profissão. Antes era mais relacionado com o serviço mesmo. Quanto melhor fosse o atendimento prestado ao paciente, melhor era. Hoje parece que isso mudou. Enfermeiros estão mais preocupados com estudos e pesquisas do que com a assistência. É lógico que o desenvolvimento da profissão, como ciência e como arte é muito importante, mas para o paciente a profissão (de enfermagem) representa ser alvo de cuidado e assistência (de enfermagem) e não se tornar apenas objeto de estudo ou pesquisa".

Houve tempo em que existia uma aura no entorno da profissão de enfermagem, tanto no sentido de preconceito em desqualificar a profissão como em santificá-la. No caso estrito dos processos de trabalho, não era fácil demonstrar à população a diferença entre os níveis hierárquicos e suas diferentes concepções de assistência. Assim, a diferenciação entre auxiliar de enfermagem, técnico e enfermeiro ainda constitui tema constante de discussões. A forma popular utilizada para diferenciar hierarquicamente as categorias era a expressão "Enfermeira de Alto Padrão", que se tornou "Enfermeira Padrão", ainda presente do imaginário social. A esse respeito, a colaboradora afirma: "Eu achava isso muito ridículo. Chamar alguém de enfermeira padrão. O que é padrão? Qual o significado da palavra padrão? Eu achava muito esquisito esse negócio de enfermeira padrão. Enfermeira é enfermeira e ponto final. O que seria muito interessante era você convencer as pessoas a usar o termo técnico correto, por exemplo, dizer eu sou auxiliar de enfermagem, eu sou técnico de enfermagem...”. 
A origem da expressão remete aos anos entre 1931 e 1949, quando houve a aprovação da Lei 775, de 6 de agosto de 1949 (Brasil, 1974a), as escolas de enfermagem ao serem criadas eram equiparadas ao padrão da Escola Ana Nery, como previsto pelo Decreto 20.109, de 1931 (Brasil, 1974b). Depois que a Lei 775/49 entrou em vigor, as escolas passaram a ser reconhecidas e não mais equiparadas. Em 1923, a Escola de Enfermagem Anna Nery, atualmente da Universidade Federal do Rio de Janeiro, era a escola oficial que seguia o modelo da Enfermagem moderna, implantada por Florence Nightingale, na Inglaterra, em 1860. Assim, a Escola era "padrão", mas foi também a profissional que passou a ser conhecida como "padrão" para distingui-la de outros que não tinham formação específica.

\section{Categoria trajetória profissional}

Nossa colaboradora graduou-se pela quarta turma da Escola de Enfermagem da Universidade de São Paulo (EEUSP), em 1949. Iniciou sua vida profissional no berçário do Hospital das Clínicas e assumiu a chefia do Centro Cirúrgico do mesmo hospital, de onde foi chamada, em 1950, para tornar-se Vice-Diretora da Escola de Enfermagem, na Bahia, fundada em janeiro de 1946. A primeira diretora dessa Escola foi Haydée Guanais Dourado, indicada por Edith de Magalhães Fraenkel, diretora da EEUSP ao Reitor da Universidade, Professor Edgard Santos. Por divergências administrativas com o reitor, Haydée Dourado afastou-se da direção e Edith de Magalhães Fraenkel foi novamente chamada para solucionar o problema, quando foi indicada Jandyra Alves Coelho, que se tornou a $2^{\text {a }}$ diretora dessa Escola, atualmente pertencente à Universidade Federal da Bahia (UFBA) e Anayde Corrêa de Carvalho, a vice-diretora. Em 1951, com o afastamento de Jandyra Coelho, Anayde tornou-se diretora da Escola, mas permaneceu no cargo o tempo suficiente apenas para que uma graduada pela primeira turma da própria Escola - Nilza Maurício Marques Garcia - pudesse assumir esse cargo. Com isso, Anayde pôde retornar como docente da EEUSP (Oliveira, 2001).

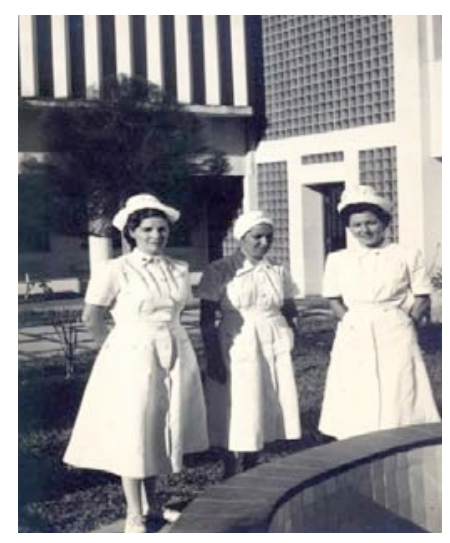

Figura 3 - Anayde Correa de Carvalho com as colegas Wanda Alves Baptista e Jandyra Alves Coelho, na Escola de Enfermagem da Bahia, 1950 e 1951. Fonte: Arquivo pessoal de Anayde Correa de Carvalho. Fotógrafo desconhecido.

Mas, em 1952, viajou com bolsa de estudos da Fundação Kellogg, para os Estados Unidos, para estudar no Teachers College, da Universidade Columbia, em Nova York, de onde regressou em 1954, para assumir funções de coordenação técnica na EEUSP. Simultaneamente, ocupou ainda o cargo de presidente da ABEn-Seção de São Paulo, de 1956 a 1958, coincidentemente, o mesmo período de realização do Levantamento de Recursos e Necessidades da Enfermagem no Brasil (Oguisso, 2006). Não seria de admirar que ela tivesse oferecido apoio e retaguarda para esse trabalho também, mas, como sempre, não deixou registro sobre isso.

$\mathrm{Na}$ função de coordenadora técnica da EEUSP, foi convidada, em 1962, para partici- 
par de um seminário para diretores e professores de cursos de pós-graduação em Enfermagem, na Jamaica, por 20 dias, patrocinado pela Organização Mundial da Saúde. Em 1963, foi novamente para os Estados Unidos para estágios e visitas de observação em escolas de enfermagem americanas, com bolsa de estudos da Fundação Kellogg. Era a preparação necessária para melhor fundamentar o programa de pós-graduação na área de administração de unidades e de serviços de enfermagem, que eram oferecidas na EEUSP, desde 1959.

Em 1970, entretanto, esse programa foi encerrado, em decorrência da implantação da Reforma Universitária (Lei 5540/1968). Embora preenchesse todos os requisitos necessários, não quis fazer o doutorado direto oferecido aos docentes da Universidade, em 1971, uma vez que seus estudos, para escrever o Documentário sobre a $\mathrm{ABEn}$, já referido, não estavam ainda prontos e não haveria tempo de concluir dentro do prazo estipulado pela Universidade se quisesse fazer, com a seriedade e o rigor metodológico que imprimia em seu trabalho. Era uma tarefa aceita para fazer com responsabilidade e também por entender que esse material seria para a ABEn e não para sua titulação própria na carreira universitária.

Além disso, entendeu que, para iniciar a pesquisa de outra temática específica para uma tese de doutorado e cumprir os ditames da Universidade, não haveria tempo para fazer como entendia que deveria ser. Dessa forma, teria que interromper o trabalho que já vinha fazendo e iniciar algo novo, quebrando totalmente o ritmo que imprimia ao Documentário que elaborava. Assim, preferiu manter-se em sua situação funcional como estava e aposentar-se, em 1979. Todo o seu preparo acadêmico, experiência profissional e dedicação ao ensino e à EEUSP não foram considerados na frieza da reclassificação funcional operada pela Universidade.

Quanto à inserção no mercado de trabalho ocorreu sem maiores problemas, pois à época, eram poucos os enfermeiros. Nossa colaboradora afirmou entusiasticamente: “... os hospitais brigavam pela gente (...)! Fui enfermeira chefe da cirurgia antes de ir para Bahia. Depois que eu voltei, só trabalhei na escola. Não pude mais retornar ao hospital".

Durante o período de governo militar, a partir de 1964, houve alguns movimentos de estudantes na EEUSP e Anayde Corrêa de Carvalho testemunhou essas intercorrências: "Foi um período muito difícil. Muito difícil mesmo. Porque um grupo de alunas era a favor da UNE (União Nacional dos Estudantes) e a favor de uma contrarrevolução, ou sei lá o que! Enfim, contra os militares. Então a escola vivia cheia de cartazes a favor da UNE ou a favor de não sei o quê e contra a ditadura, contra os militares. Tinha o grupo da direita e o grupo da esquerda. O da esquerda era muito mais atuante. E voltavam às vezes de madrugada porque ficavam lá na UNE e as da direita diziam ficar lá ouvindo aquele bafafá da UNE até se cansarem. Elas cansavam e vinham embora, e a turma da esquerda continuava, então elas votavam naquilo que era do interesse da esquerda. Então teve um período difícil da escola por causa disso, porque havia essa diferença entre o grupo da direita e o grupo da esquerda. Não havia nenhum conflito não, havia apenas preocupações das meninas da esquerda ficarem muito ativas e haver esse interesse em querer sair a toda hora, querer participar e colocar cartaz na escola inteirinha. Era esse o trabalho que dava. Eu acho que teve uma, sim, que foi detida (...) que teve problema com os militares. Eu tenho uma vaga ideia, não estou bem lembrada".

À pergunta sobre se havia algum tipo de 
"orientação" do governo com relação às disciplinas ministradas, Anayde Corrêa de Carvalho respondeu: "Não. Não tinha, mas eu fui chamada para falar sobre uma das professoras. Parece que uma das professoras era meio da esquerda, ou alguma coisa assim, então quando os militares tomaram o poder houve aquela estória de procurar quem era e quem não era. Eu fui chamada, eu e outras professoras fomos chamadas para falar lá. Foi uma situação muito ruim, mas, na verdade, a gente não falou nada mesmo porque eu não ia falar contra uma colega de jeito nenhum, mas foi uma situação muito desagradável". Sobre alguma consequência com essa colega, ela respondeu: "Não. Não! Ela era apenas uma entusiasta da enfermagem".

Em uma época de conquistas de espaços e de muitos desafios, os contatos pessoais com grandes ícones da enfermagem brasileira ficaram marcados com uma mescla de carinho e orgulho especial, como pode ser observada nas falas de nossa colaboradora, que teve sua irmã mais nova, Amália Correa de Carvalho, como líder de grande projeção nacional e internacional da enfermagem brasileira. Mas, lembrou-se de muitas outras: "A Glete (de Alcântara), trabalhou demais pela ABEn e também pela Revista (Brasileira de Enfermagem). Outra que trabalhou muito foi a Haydée Dourado (...), a Marina de Andrade Rezende, a Waleska Paixão, diretora lá da Escola Anna Nery (...) Taka é de uma responsabilidade fora do comum (...) Ainda tem a Victoria (Secaf) que também continua na enfermagem. .. a Lore (Cecília Marx) que acho que também continua. A Irmã Tereza (Notarnicola), eu não posso esquecer o nome da Irmã Tereza que trabalhou demais também pela enfermagem toda. (...) Os tempos mudaram, pois o tempo da Dona Edith (Magalhães Fraenkel) era outro, diferente, e de Dona Maria Rosa (de Sousa Pinheiro), também".

\section{Categoria visão futurista}

A visão de futuro demonstra a preocupação com a qualidade da assistência prestada pela enfermagem. Seria necessário que a profissão trabalhasse mais para a construção do futuro desejado, planejando a conquista de mais espaço, ... "Eu gostaria que a enfermeira tivesse um cuidado muito maior com o paciente, que levasse mais em consideração a pessoa (...), porque hoje a parte técnica de serviço é considerado mais importante (...). Essa história de humanização é velha, (...) na Escola já falavam em humanização. A gente já falava em humanização. E essa questão é muito importante para enfermagem e tenho até a impressão de que enfermagem seria mais mesmo para isso, porque o contato constante com as pessoas que tratam dele é muito importante. E não é só assim dar uma injeção e não falar com o paciente. E conversar é estabelecer comunicação".

Apesar de estar há décadas afastada da enfermagem, em geral, e principalmente da prática da assistência de enfermagem, é notável sua preocupação com a humanização dessa assistência e com o trato mais personalizado de cada usuário do serviço de saúde. Possivelmente, suas reiteradas cirurgias e hospitalizações que sofreu em São Paulo e também em Ribeirão Preto, estejam na raiz de suas observações.

O espaço ocupado pela enfermagem no âmbito da saúde e seu reconhecimento está presente como outra grande preocupação em seu relato, assim como surgem a figura da hegemonia médica e a relação de poder que aparecem no término da entrevista: ... "Eu acho essa parte importante, ser a ponte. Porque o médico fala e a enfermeira interpreta, porque ela é que está mais perto do paciente, eu acho isso importante. Eu acho certo. (...) Às vezes eu acho que a enfermeira quer avançar um pouquinho 
na função do médico. Não é de hoje que eu ouço falar que a enfermeira faz prescrição, prescrição dos cuidados de enfermagem, prescrever isso, prescrever aquilo. Não basta prescrever. É preciso que o cuidado seja efetiva e devidamente realizado, senão pela própria enfermeira, pelo técnico ou auxiliar com supervisão. Portanto, a tarefa do enfermeiro não termina com a prescrição do cuidado, mas com o cuidado prestado como se deve. Deveria haver mais preocupação e vigilância com essa atenção ou assistência direta de enfermagem ao paciente".

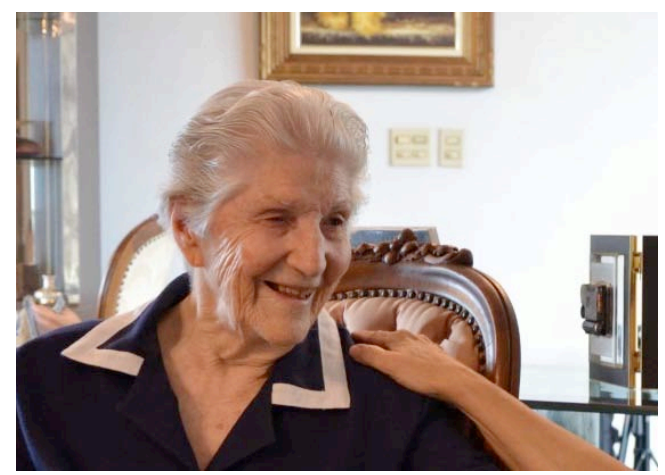

Foto 4 - Anayde Correa de Carvalho em fotografia de maio de 2013. Fonte: Arquivo pessoal Profa Dra Taka Oguisso. Fotógrafo: Marcos Antonio Vieira.

Assim, para a nossa colaboradora, é preciso que profissionais de enfermagem na área assistencial direcionem mais sua atenção para a devida assistência aos pacientes, alvo principal da profissão. E os docentes devem ensinar e dar o exemplo de como cuidar dos pacientes com a devida ciência, arte e técnica, sem descuidar do ideal que deveria permear todas as ações de enfermagem. Como um conselho para as próximas gerações, Anayde Corrêa de Carvalho diz: "Agora é que é a estória. Depende muito de a pessoa querer, ou não. Se a pessoa tiver tendência, eu aconselho que faça. Se ela disser: não sei se faço ou se não faço, diria: não faça. O que você quer saber é se eu acho (a enfermagem) uma profissão boa? Eu acho. Eu acho uma profissão muito boa mesmo. Eu achava melhor a enfermagem no tempo em que a enfermeira cuidava mesmo do paciente, tratava o paciente como gente, como pessoa humana. Hoje a coisa é um pouco diferente. As pessoas fazem as coisas assim... digamos benfeitas, mas sem considerar o paciente como pessoa. É a impressão que eu tenho. O que falta é mais consideração com o paciente. Não pensar tanto na ficha, no desenvolvimento tecnológico da profissão; pensar mais no paciente como ser humano digno de receber toda atenção e consideração. $E$ exatamente isso! Eu já estive internada várias vezes, então a gente sente a diferença entre uma pessoa e outra. Tinha uma que vinha e falava 'o e coisa e tal'. Tinha outra que vinha aplicar injeção e não falava nem 'oi, nem nada'. Então há uma diferença muito grande nisso. É quando você chega e diz para o paciente: 'Bom dia, como amanheceu?' Ou chegar e dar uma injeção, ou fazer um tratamento e depois sair sem dizer nada. É essa diferença, que eu acho".

Sobre isso, ela aponta que existe diferença na equipe de enfermagem entre o auxiliar e o técnico de enfermagem: "Tem. A enfermeira tem uma postura diferente. Ela entra no quarto e também pergunta. Mas o problema é que raramente aparece. Antigamente, veja bem, eu não trabalhei em hospital particular, eu só trabalhei no HC, que era bem diferente. Você tinha que dar o cuidado de enfermagem. Você tinha 40 pacientes para cuidar. Você tinha de visitar todos os pacientes, todos os dias e saber como eles estavam, dando atenção e ouvindo o paciente. Agora hoje, no hospital particular onde eu estive, a enfermeira entrava. Eu fiquei lá uma semana e a enfermeira entrou uma única vez, que eu vi. Então é uma diferença muito grande. Hoje você tem o aumento de trabalho, 
parece que elas têm pouco tempo para dar essa atenção. Por isso há uma grande diferença sim. Bem, eu estou falando assim, sem atuar. Eu estou falando o que eu vejo, mas se eu continuasse a atuar na prática talvez eu pensasse diferente, não sei”.

A história descrita acima marca a trajetória acadêmica e profissional de uma personalidade marcante da História da Enfermagem que veio do interior de São Paulo, mas ainda assim uma grande cidade - Ribeirão Preto - para estudar enfermagem na capital, na Escola de Enfermagem da Universidade de São Paulo. Depois iniciou sua trajetória profissional na assistência de enfermagem no Hospital das Clínicas, e tornou-se uma importante docente, tendo colaborado diretamente com Edith de Magalhães Fraenkel e com Maria Rosa de Sousa Pinheiro, as duas primeiras diretoras da EEUSP, mas, estava sempre na retaguarda, para dar consistência e cobertura técnica e administrativa a todos os atos delas como dirigentes educacionais.

Eis a história de uma enfermeira incomum, aquela que buscava não aparecer, nem ficar sob a luz de holofotes, nem títulos acadêmicos, nem honrarias, apenas trabalhar para que outros pudessem aparecer e fazer boa figura. É a história de uma profissional, preocupada com o cuidado de enfermagem que deve ser prestado a cada paciente. Embora a colaboradora enfatizasse a atividade burocrática no assim chamado "escritório técnico" da Escola, ela ministrava também a disciplina "Administração aplicada à Enfermagem" e, como boa administradora, sabia organizar e implantar sistemas de trabalho e sabia ensinar alunos da graduação e pós-graduação, sendo, por isso mesmo, escolhida várias vezes como paraninfa de turmas, fatos que sua modéstia não lhe permite mencionar. Todavia, artigo de sua au- toria (Carvalho, 1968) foi publicado na Revista da Escola de Enfermagem da EEUSP, onde se identifica como professora de Administração aplicada à Enfermagem. Essas são as características da colaboradora deste estudo: Anayde Corrêa de Carvalho.

\section{CONSIDERAÇÕES FINAIS}

Faz-se necessário continuar e aprofundar estudos para a construção da identidade profissional da enfermagem, ainda latente e semioculta. As trajetórias profissionais de figuras como a da enfermeira retratada demonstram quanto ainda se tem que progredir, não apenas para consolidar a imagem da identidade profissional como também para construir o próprio futuro da enfermagem, da forma desejada pela classe. Robert Olson (1997) já afirmava que o "grande desafio não é prever o futuro, mas sim construí-lo". Cada um dos profissionais de enfermagem precisa crer que é possível criar e construir esse futuro desejado para a Enfermagem e desenvolver estratégias para alcançar as metas que levarão a esse porvir ansiado. Uma tendência que se delineia para o futuro da Enfermagem é a necessidade e, talvez, obrigatoriedade de uma avaliação e reavaliação periódica e sistemática dos conhecimentos teóricos e práticos da enfermagem, como requisito para a continuidade no exercício da profissão, não apenas dos enfermeiros como de todos os membros da equipe de enfermagem.

É preciso, portanto, reafirmar que é importante consolidar a imagem de humanidade, tecnicidade, modernidade, intelectualidade e cientificidade que Florence Nightingale trouxe à profissão. Para a entrevistada, a esses aspectos seria importante acrescentar ainda "fé inabalável e amor profundo pela profissão" como citou Anayde Corrêa de Carvalho no discurso de 1968, em homenagem a Edith de Magalhães 
Fraenkel, dizendo que a vida dela era uma "fervorosa devoção à enfermagem" (Carvalho, 2012).

Anayde Corrêa de Carvalho demonstrou latente preocupação com a questão da humanização da assistência de enfermagem, apontando o excesso de trabalho burocrático que consome o tempo da enfermeira, que precisa priorizar mais o estar ao lado do paciente e de cuidar ela mesma. Nessa ação de cuidar é igualmente importante que a enfermeira seja a ponte entre o saber médico e o paciente. É o que ensina Anayde Corrêa de Carvalho.

Além de desenvolver o nível de excelência da ciência de enfermagem, através de pesquisas e estudos, é necessário assegurar competência técnica no exercício da profissão aliado ao espírito humanitário. Para isso é preciso acrescentar mais calor humano, em cada gesto da ação de cuidar, em cada palavra e até mesmo no tom de voz, e transmitir através da expressão corporal a tranquilidade, segurança e empatia de quem realmente gosta do que faz e faz porque gosta.

\section{REFERÊNCIAS}

- Bardin, L. (2008) Análise de conteúdo. Edições 70, Rio de Janeiro.

- Barreira, I.A. (2006) Depoimento escrito. En Associação Brasileira de Enfermagem - Documentário, 1926-1976 (Carvalho, A.C.), 2 a edição, ABEn, Brasília, pp. contracapa.

- Brasil. (1974a) Lei n 775, de 6 de agosto de 1949. Dispõe sobre o ensino de enfermagem no País e dá outras providências. En Enfermagem, legislação e assuntos correlatos (Ministério da Saúde ed.), 3ª.ed. Fundação Serviços de Saúde Pública, Rio de Janeiro v.I, pp.154-157.

- Brasil. (1974b) Decreto no 20.109, de 15 de junho de 1931. Regula o exercício da enfermagem no Brasil e fixa as condições para a equiparação das escolas de enfermagem e instruções relativas ao processo de exame para revalidação de diplomas. En Enfermagem, legislação e assuntos correlatos (Ministério da Saúde ed.), $3^{\text {a }}$.ed. Fundação Serviços de Saúde Pública, Rio de Janeiro v.I, pp.68-72.

- Carvalho, A.C. (1968) Plano de cuidados como uma das funções do enfermeiro-chefe. Revista da Escola de Enfermagem da USP 2(1), 108-117.

- Carvalho, A.C. (1976) Associação Brasileira de Enfermagem: Documentário, 1926-1976. ABEn, Brasília.

- Carvalho, A.C. (2012) Edith de Magalhães Fraenkel 2a Ed, organizada por Oguisso, T. e Nichiata, L.Y.I. FAPESP/EE/USP, São Paulo.

- Meihy, J.C.S.B. (2002) Manual de História Oral. $4^{\circ}$ ed. Loyola, São Paulo.

- Oguisso, T. (2006) Nota sobre a autora. En Associação Brasileira de Enfermagem - Documentário, 1926-1976 (Carvalho, A.C.), 2a edição, ABEn, Brasília, pp. 475-6.

- Oliveira, M.I.R. (2001) Emergência e inserção da Escola de Enfermagem na comunidade acadêmica da Universidade da Bahia, 1946 a 1956. En Memorial da Escola de Enfermagem 1946-1996. (Dumet, J.D.), Universidade Federal da Bahia, Escola de Enfermagem, Salvador, pp. 17-49.

- Olson, R. (1997) Future directions: reports on future techniques for nursing: Geneva 1997. Institute for Alternative Futures, New York.

- Sanna, M.C. (2011) Biografia. En Pesquisa em História da Enfermagem (Oguisso, T., Souza Campos, P.F. y Freitas, G,F. org.), Manole, Barueri pp.302-303. 